\title{
Experimental investigation of photocatalytic effects of concrete in air purification adopting entire concrete waste reuse model
}

Yidong $\mathrm{Xu}^{1}$, Wei Chen ${ }^{1}$, Ruoyu Jin ${ }^{2, *}$, Jiansheng Shen ${ }^{1}$, Kirsty Smallbone ${ }^{2}$, Chunyang Yan $^{1}$, Lei $\mathrm{Hu}^{1}$

1. Ningbo Institute of Technology, Zhejiang University, Ningbo, China;

2. School of Environment and Technology, University of Brighton, Brighton, UK

*: Corresponding author, Phone: +44 (01273) 642289, Email: R.Jin@brighton.ac.uk

\begin{abstract}
This research investigated the capacities of recycled aggregate concrete adopting entire concrete waste reuse model in degrading $\mathrm{NO}_{2}$. Two major issues within environmental sustainability were addressed: concrete waste reuse rate and mitigation of hazards substances in the polluted air. The study consisted of two stages: identification of proper replacement rates of recycled concrete wastes in new concrete mixture design, and the evaluation of photocatalytic performance of recycled aggregate concrete in degrading $\mathrm{NO}_{2}$. It was found that replacement rates up to $3 \%, 30 \%$, and $50 \%$ for recycled power, recycled fine aggregate, and recycled coarse aggregate respectively could be applied in concrete mixture design without deteriorating concrete strength. Recycled aggregates contained both positive attributes ("internal curing") and negative effects (e.g., lower hardness) to concrete properties. It was found that $30 \%$ to $50 \%$ of natural coarse aggregate replaced by recycled coarse aggregates coated with $\mathrm{TiO}_{2}$ would significantly improve the photocatalytic performance of concrete measured by degradation rate of $\mathrm{NO}_{2}$. Micro-structures of recycled aggregates observed under microscope indicated that soaking recycled aggregates in $\mathrm{TiO}_{2}$ solution enabled $\mathrm{TiO}_{2} \underline{\text { resulted }}$ in whiskers that filled the porosity within recycled aggregates which enhanced concrete strength.
\end{abstract}

Keywords: Recycled aggregate concrete, Environmental sustainability, Photocatalyst, Concrete waste, Concrete mixture design 


\section{Introduction}

Air pollution caused by automobile exhaust has deteriorated the natural environment in metropolitan areas of many developing countries such as China. Heavy traffic is causing high concentration of hazardous air pollutants, such as $\mathrm{NO}_{\mathrm{x}}$ and $\mathrm{VOC}$, which not only lead to environmental deterioration but also trigger public health problems $[1,2]$. Owing to the excellent air purification ability of photocatalyst materials, the application of titanium dioxide $\left(\mathrm{TiO}_{2}\right)$ in cement concrete pavement is an emerging technology in removing $\mathrm{NO}_{\mathrm{x}}$.

Research targeting photocatalytic behavior of cementitious products containing $\mathrm{TiO}_{2}$ can be found in previous studies. For example, Yang [3] synthesized a $\mathrm{TiO}_{2}$ porous microspheres material for photocatalytic depollution purpose; Macphee and Folli [4] discussed the application of $\mathrm{TiO}_{2}$-based photocatalysts to concrete and concluded that concrete surface should maximize photocatalyst accessibility; Faraldos and Kropp [5] found that photocatalytic coatings of $\mathrm{TiO}_{2}$ nanoparticles were highly effective in treating $\mathrm{NO}_{x}$ pollution when applied to concrete surfaces; Poon $[6,7]$ investigated the effectiveness of incorporating $\mathrm{TiO}_{2}$ in producing concrete pavement exposed to NO.

With the rapid growth of infrastructure development in China, construction and demolition (C\&D) wastes account for a large portion of wastes and their generation has been increasing rapidly [8]. Concrete waste constitutes the major part of construction waste, accounting for about $50 \%$ of the total waste generated [9]. It was estimated that approximately 638 million tons of waste concrete would be produced annually by 2020 [10]. The urgency of decreasing $\mathrm{C} \& \mathrm{D}$ wastes to reduce the demand on landfilling space and to enhance waste diversion has driven China's movements towards sustainability [11]. The difficulties of disposing waste 
concrete have motivated research and application of reusing demolished concrete as recycled materials [12].

Processing concrete waste would generate three major types of recycled products, namely recycled coarse aggregate (RCA), recycled fine aggregate (RFA) and recycled powder (RP) [13]. Significant research work has been performed on the application of recycled aggregates (RAs) in recycled aggregate concrete (RAC). These studies can be generally categorized into RCA-based, RFA-based, and RP-based research of RAC. In the RCA-based RAC studies, Limbachiya [14] showed that up to 30\% RCA had no significant effect in concrete strength, but there was a gradual reduction as the RCA content increased; Tam et al. [15] found that inferior quality of demolished concrete would lower the quality of both RAs and RAC; Xiao et al. [16] concluded that the compressive strength of RAC would decrease as RCA replacement percentages increased; Zhao et al. [17] revealed that RAC with a pre-wetting process had lower compressive strength and higher $\mathrm{Cl}^{-}$diffusion coefficient, but a smaller shrinkage value. In the RFA-based research of RAC, Shi et al. [18] inferred that owing to the higher water adsorption and lower strength of RFA, the utilization of RFA in RAC was more difficult compared to that of RCA; Fan et al. [19] found that the content of RFA was an important factor affecting RAC; Geng and Sun [20] indicated that increased RFA amount would decrease the carbonation resistance of RAC. In the RP-targeted research within RAC, existing studies have been mostly focused on the reuse of RP from waste clay bricks as cement replacement [21-23]. Koshiro and Ichise[24] established an entire concrete waste reuse model (ECWRM) to fully reuse wastes from demolished concrete. Both RCA and RFA were reused in new concrete mixture design and RP was also reused as a material for clay tiles. 
A review of these aforementioned studies in both photocatalytic concrete and RAC indicates the research gaps in that: 1) there have been limited studies of RAC adopting ECWRM and there could be a higher utilization rate of waste concrete in the new concrete production; 2) there have been insufficient research on identifying the proper replacement rates of each type of recycled products (i.e., RCA, RFA, and RP) in RAC mixture design; 3) limited studies have bridged the photocatalytic cementitious products and RAC by allowing RAC to have photocatalytic capacity. Besides, a review of other relevant existing studies [25-30] on mechanical properties, environmental performance, and micro-structure analysis of concrete containing recycled contents infers that most of these studies focused on concrete properties (e.g., strength, durability, and impacts on the environment), with limited research on exploring the "passive strategy" of sustainable concrete in addressing environmental challenges such as mitigating hazardous substances in the polluted air.

This paper aims to investigate the photocatalytic performance of RAC adopting ECWRM by addressing two major issues in China's environmental sustainability: overwhelming C\&D wastes and air pollution. The objectives of the study can be described as: 1) to collect RCA, RFA, and RP from demolished concrete; 2) to identify appropriate substitution rates of each of the three types of recycled products in RAC adopting ECWRM without significantly deteriorating RAC's mechanical properties; 3) to test and evaluate the performance of RAC coated with $\mathrm{TiO}_{2}$ as the photocatalysts in degrading $\left.\mathrm{NO}_{2} ; 4\right)$ to observe and analyze the microstructure of RAs intertwining with $\mathrm{TiO}_{2}$ particles by soaking $\mathrm{RAC}$ debris in $\mathrm{TiO}_{2}$ solution. This study serves as the initial investigation of developing the RAC capacity for depollution purpose, and would lead to future research on applying RAC products in photodegrading hazardous 
substances.

\section{Materials and methods}

The experimental procedure in this research can be divided into two major stages after collecting RP, RFA, and RCA from waste concrete, namely identification of appropriate substitution rates for each type of recycled products to their counterparts (i.e., cementitious materials including Portland cement and fly ash, natural fine aggregate or NFA, and natural coarse aggregate or NCA) in concrete mixture design, and tests of photocatalytic effect in degrading $\mathrm{NO}_{2}$ for concrete specimens containing RP, RFA, and RCA, where RFA and RCA are coated with $\mathrm{TiO}_{2}$.

\subsection{Materials used}

Type 42.5 commercial Portland cement according to Chinese Standards Common Portland Cement GB175-2007 [31] was used in this study. Class II fly ash conforming to Chinese Standard Fly Ash Used for Cement and Concrete GB/T1596 [32] was used as the supplementary cementitious material. The water-reducing rate of polycarboxylate superplasticizer was $25 \%$.

The demolished concrete with original compressive strength at $30 \mathrm{MPa}$ was crushed and then obtained particles were sieved into differently-sized particles. RCA and RFA used in this study ranged from $5 \mathrm{~mm}$ to $25 \mathrm{~mm}$ and from $0.16 \mathrm{~mm}$ to $5 \mathrm{~mm}$ respectively. The remaining powders were pulverized by a vibrating mill to obtain the specific surface area of $400 \mathrm{~m}^{2} / \mathrm{kg}$ for RP. The crushing process and the three major types of recycled products are shown in Fig. 1. 


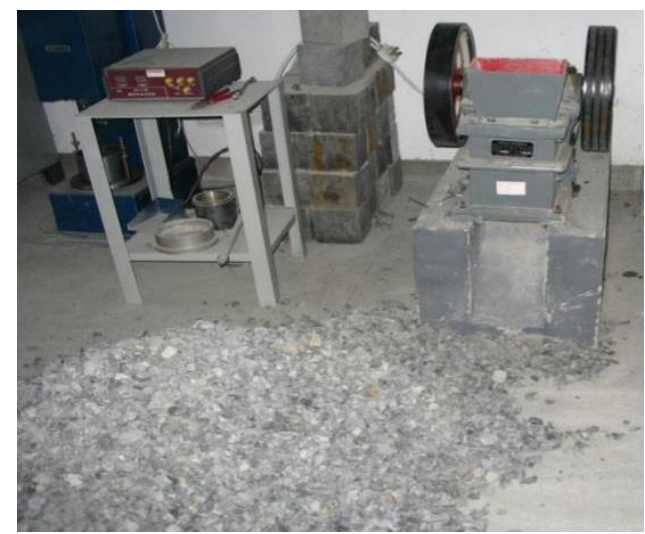

(a) Jaw crusher

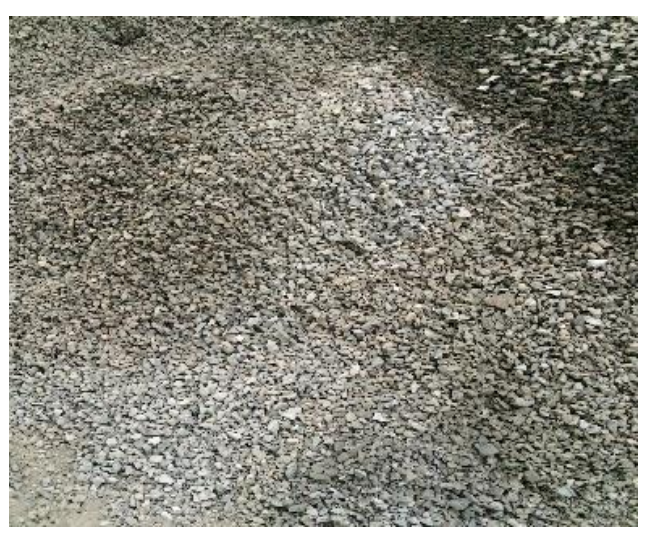

(c) RFA

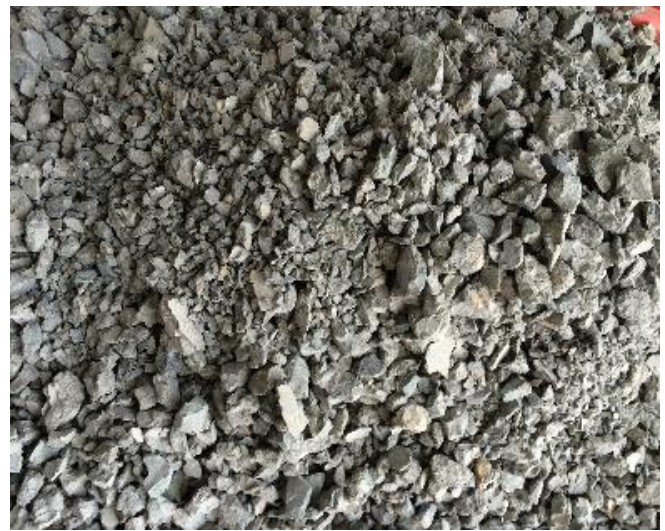

(b) RCA

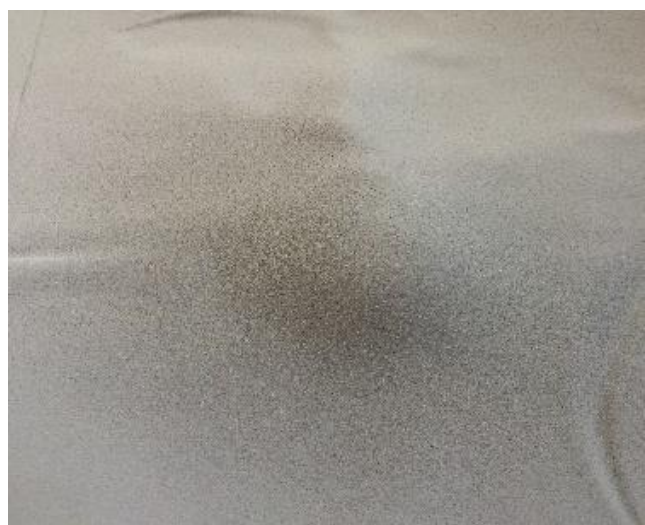

(d) RP

Fig. 1. Waste concrete processing

NCA in this research was obtained by crushing limestone and had the same size as RCA.

River sand was used as NFA in concrete mixture. NFA used for cement mortar preparation conformed to China ISO Standard Sand GSB 08-1337 [33]. Following Chinese standards, Pebble and crushed stone for construction GB/T 14685 [34] and Sand for construction GB/T 14684 [35], the physical and mechanical properties of aggregates were tested. The tests results are summarized in Table 1 and Table 2.

Table 1. Properties of coarse aggregate

\begin{tabular}{|c|c|c|c|c|c|}
\hline $\begin{array}{c}\text { Aggregates } \\
\text { type }\end{array}$ & $\begin{array}{c}\text { Apparent } \\
\text { density }\left(\mathrm{kg} / \mathrm{m}^{3}\right)\end{array}$ & $\begin{array}{c}\text { Bulk } \\
\text { density }\left(\mathrm{kg} / \mathrm{m}^{3}\right)\end{array}$ & $\begin{array}{c}\text { Sediment } \\
(\%)\end{array}$ & $\begin{array}{c}\text { Surface dry water } \\
\text { absorption rate (\%) }\end{array}$ & $\begin{array}{c}\text { Crushing } \\
\text { value (\%) }\end{array}$ \\
\hline RCA & 2480 & 1295 & 0.9 & 2.8 & 14.9 \\
\hline NCA & 2660 & 1430 & 0.6 & 0.9 & 8.1 \\
\hline
\end{tabular}


Table 2. Properties of fine aggregate

\begin{tabular}{|c|c|c|c|}
\hline \multirow{2}{*}{ Aggregate type } & Apparent density & Bulk density & Sediment \\
\cline { 2 - 4 } & $\left(\mathrm{kg} / \mathrm{m}^{3}\right)$ & $\left(\mathrm{kg} / \mathrm{m}^{3}\right)$ & $(\%)$ \\
\hline RFA & 2430 & 1410 & 12.3 \\
\hline NFA & 2620 & 1565 & 1.5 \\
\hline
\end{tabular}

The photocatalyst used in this study was $\mathrm{TiO}_{2}$ from ZIXILAI Environmental Protection Technology Co., Ltd., and the physical properties are listed in Table 3.

Table 3. Properties of $\mathrm{TiO}_{2}$

\begin{tabular}{|c|c|}
\hline Appearance & White powder \\
\hline Average crystal size & 10nm \\
\hline Crystal structure & Mischcrystal $\mathrm{TiO}_{2}$ (Anatase and Rutile) \\
\hline $\mathrm{TiO}_{2}$ Content & $>96$ \\
\hline Photocatalytic efficiency & $\geq 68$ \\
\hline
\end{tabular}

$\mathrm{TiO}_{2}$ powders were ultrasonically dispersed into distilled water to form suspension with concentration at $0.6 \%$. RAs were soaked in the $0.6 \% \mathrm{TiO}_{2}$ solution for 24 hours. Afterwards, soaked aggregates were oven dried at controlled temperature of $60^{\circ} \mathrm{C}$. Following the natural cooling procedure, RCA and RFA with photocatalytic components were obtained. They are denoted as RCA-T and RFA-T respectively.

\subsection{Test program for photocatalytic activities}

There are currently no photocatalytic test standards for cement-based materials. Based on the Chinese national standard Test Method of Photocatalytic Materials for Air Purification $G B / T 23761$ [36], the researchers designed and manufactured the test facility for measuring the photocatalytic efficiency on hazardous substances. Fig. 3 displays the schematic diagram of the cubic box containing light source and the reactor where the RAC adopting ECWRM is placed. Fig.4 shows the whole test facility in evaluating the photocatalytic activities of concrete specimens. 


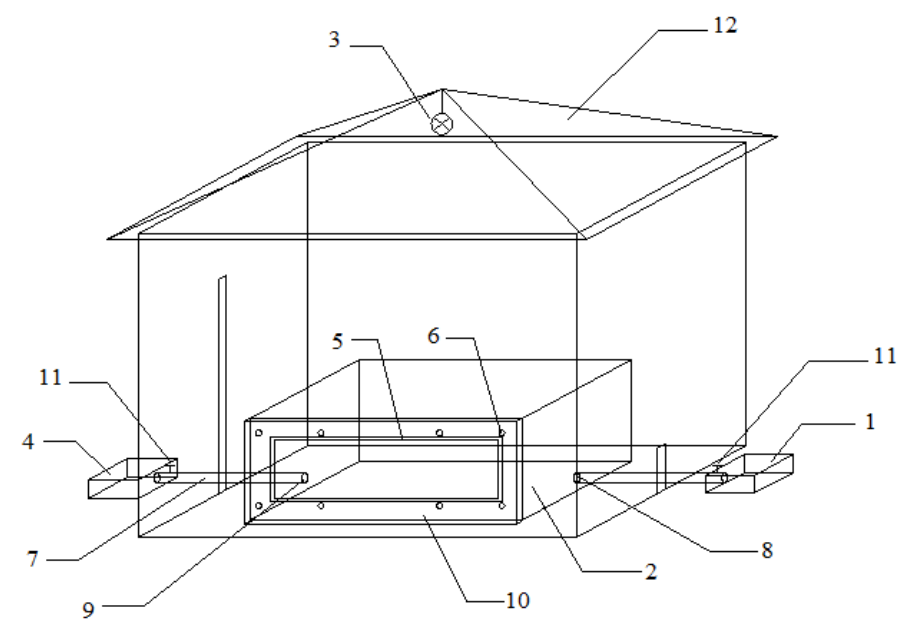

1: Gas supply source; 2: Reactor; 3: UV light source; 4: exhaust analyzer; 5: Rubber ring; 6: Screws; 7: Airway; 8: Air inlet; 9: Air outlet; 10: Transparent gate; 11: Valve; 12: Reflective Sheltering

Fig.3. Schematic diagram of the cubic box for testing photocatalytic activity

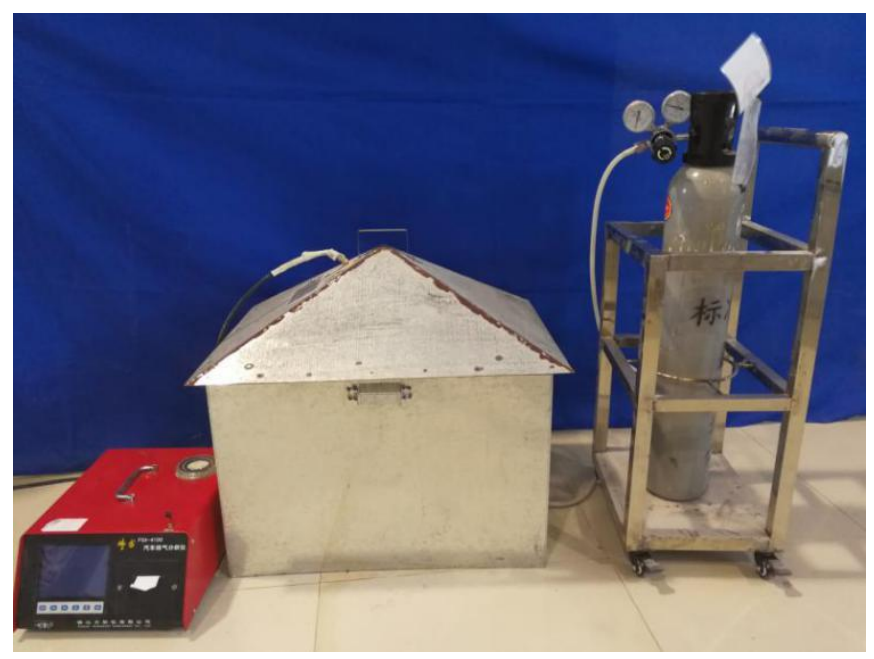

Fig.4. The whole test facility for photocatalytic activities

The test facility shown in Fig. 3 and Fig.4 consisted of the major components including the cubic box with light source, reactor, gas supply, and exhaust analyzer.

According to the Chinese standard of GB/T 30809-2014 UV light sources for testing properties of photocatalytic materials [37], the GCH24S13 model was adopted as the UV light source. The twin tube photocatalytic UV light source had a diameter of $13 \mathrm{~mm}$ with its dominant wavelength between $365 \mathrm{~nm}$ and $420 \mathrm{~nm}$.

The reactor, as shown in Fig.5, was used to put the concrete specimen. The reactor was 
made of transparent plexiglass to ensure that the concrete specimen would fully receive the UV light.

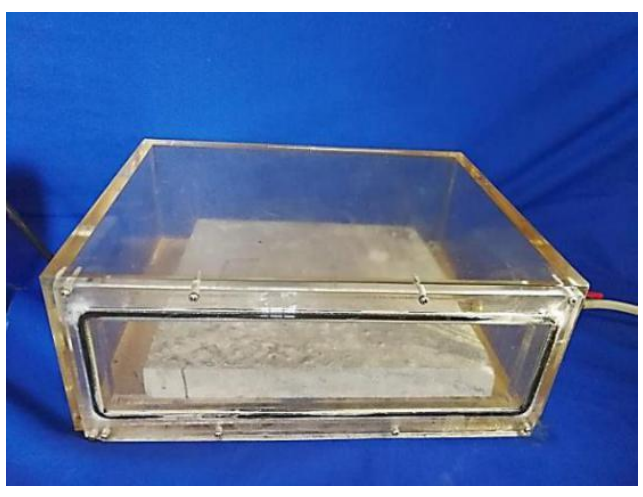

a) Reactor made of transparent plexiglass

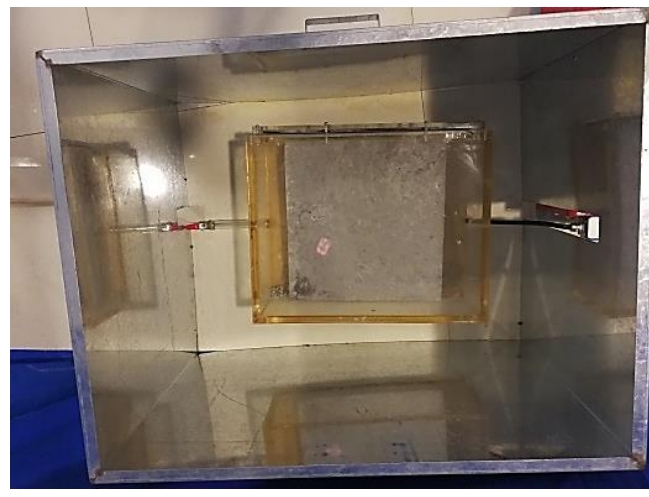

b) Cubic box hosting the reactor

Fig.5. Reactor and the cubic box

It can be seen in Fig.5 that the opening was set at the reactor's top cover for placing the concrete specimen. Eight thread drilled holes were set around the edges of the opening. A plexiglass plate whose edges were pasted with rubber ring was used to cover the opening. The eight thread drilled holes at the four edges of the plexiglass plate overlapped the drilled holes set at the opening. Therefore, the plexiglass plate and the reactor can be connected by tightening the screws targeting the eight thread drilled holes. The reactor will then be firmly sealed up by squeezing the rubber ring. A valve opening was designed at both left and right sides of the reactor to control the gas inflow and outflow during the experiment.

A cubic and non-transparent box made of iron, as shown in Fig.3 and Fig.5-b), was designed to place the reactor inside of it. The top cover and four sides of the cubic box are shown in Fig.6. 


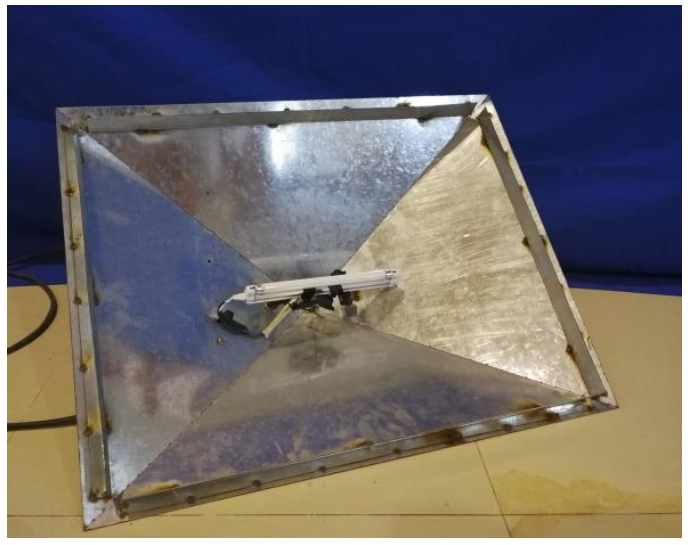

a) The top cover of the cubic box

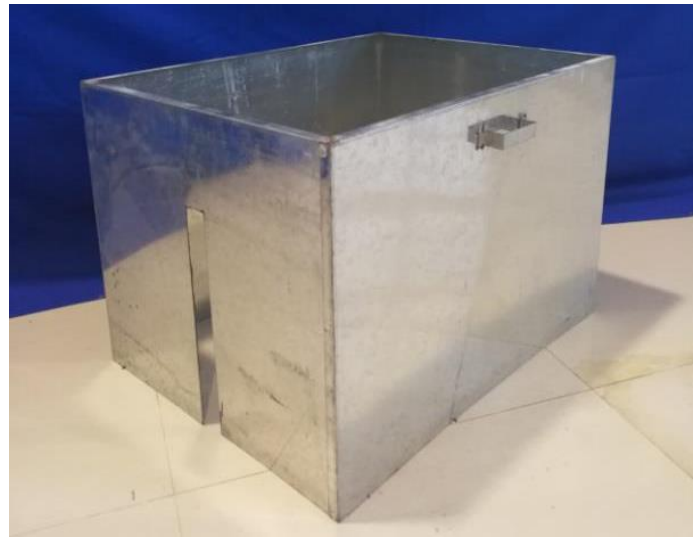

b) Four sides of the cubic box hosting the reactor

Fig.6. The cubic box hosting the reactor

It can be seen in Fig. 5 and Fig.6 that the iron-made cubic box serves as the sheltering device to prevent natural lighting coming into the reactor. The aforementioned UV light source could be placed at the top of the cubic box providing the UV lighting meanwhile minimizing the effects of natural lighting in photocatalytic activities.

The exhaust gas analyzer adopted in this research was FGA-4100 manufactured in Foshan China. It was used to test and measure the photocatalytic performance.

\section{The mixture design of photocatalytic concrete materials}

\subsection{The influence of RP on the properties of cementitious materials}

Three different mix proportions within cement pastes were designed as shown in Table 4 . Cement was partially replaced with RP at substitution rates of $10 \%$ and $30 \%$.

Table 4. Proportion of cement paste produced with recycled powder (g)

\begin{tabular}{|c|c|c|c|}
\hline Code & Cement & RP & Water \\
\hline CRP-0 & 500 & 0 & 200 \\
\hline CRP-10 & 450 & 50 & 200 \\
\hline CRP-30 & 350 & 150 & 200 \\
\hline
\end{tabular}

The hydration properties of cement paste produced with RP were evaluated by the nonevaporable water $\left(W_{n e}\right)$ at selected ages. The loss on ignition method adopted in previous studies 
[38-40] was used to determine the amount of non-evaporable water. Crushed samples from hardened pastes at different ages (D3, D28, D60, and D90) were soaked in absolute ethyl alcohol to terminate further hydration. Samples were then pulverized and oven-dried for $24 \mathrm{~h}$ at $105{ }^{\circ} \mathrm{C}$, followed by being heated in a muffle furnace at $1050{ }^{\circ} \mathrm{C}$ for $3 \mathrm{~h}$. According to the weight loss of samples between $105^{\circ} \mathrm{C}$ and $1050{ }^{\circ} \mathrm{C}$, the $W_{n e}$ values were calculated following Equations (7) and (8):

$$
W_{n e}=\frac{m_{105}-m_{950}}{m_{950}}-\frac{r_{c r}}{1-r_{c r}}
$$

where $W_{n e}$ is the non-evaporable water content, $m_{105}$ and $m_{900}$ are the sample weights measured at $105^{\circ} \mathrm{C}$ and $950{ }^{\circ} \mathrm{C}$ respectively;

$$
r_{c r}=p_{c} r_{c}+p_{r} r_{r}
$$

where $p_{c}$ and $p_{r}$ denote the weight percentages of cement and RP respectively, and $r_{c}$ and $r_{r}$ are the loss on ignition of cement and RP respectively.

As shown in Fig. 7, the amount of non-evaporable water content within cement paste increased with age and decreased with RP percentage. The $W_{n e}$ value of the control sample (CRP-0) on D90 was 16.58\%. While for CRP-10 and CRP-30 samples, the $W_{n e}$ values at D90 were $14.37 \%$ and $11.85 \%$ respectively, decreased by $13.33 \%$ and $28.50 \%$ respectively compared to the control sample. The $W_{n e}$ value indicates the amount of hydration product. Due to the low pozzolanic reaction of RP, the adoption of RP as cement replacement inevitably leads to the reduction of hydration products. 


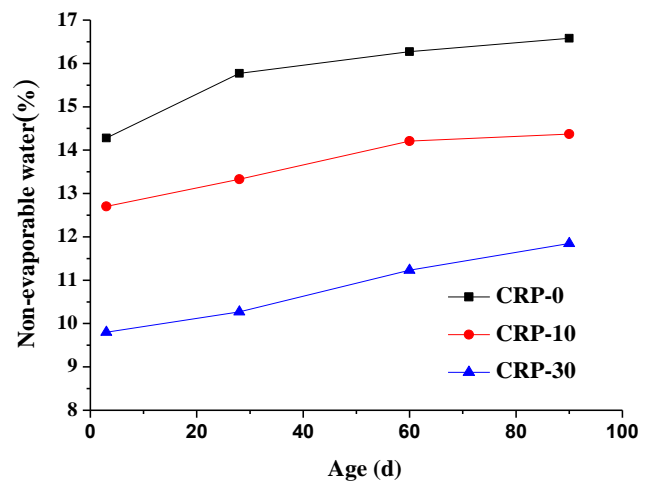

Fig.7. Influence of RP on non-evaporable water within cement paste

In order to determine the effect of RP percentage on the mechanical properties of cementbased materials, four mortar specimens were prepared and cured conforming to Chinese Standard Method of testing cements-Determination of strength GB/T 17671. In these mortar specimens, cement was partially replaced with RP at three different substitution rates (i.e., $3 \%$, 5\% and 10\%). Detailed mix proportions are listed in Table 5. The compressive strength and flexural strength were tested on different ages (i.e., D3, D28, and D56).

Table 5 Mix proportion of cement mortar produced with RP $(\mathrm{g})$

\begin{tabular}{|c|c|c|c|c|}
\hline Code & Cement & RP & $\begin{array}{c}\text { ISO standard } \\
\text { sand }\end{array}$ & Water \\
\hline A-0 & 450 & 0 & 1350 & 225 \\
\hline A-3 & 436.5 & 13.5 & 1350 & 225 \\
\hline A-5 & 427.5 & 22.5 & 1350 & 225 \\
\hline A-10 & 405 & 45 & 1350 & 225 \\
\hline
\end{tabular}

The influence of RP content on the mechanical properties of mortar is illustrated in Fig. 8. When RP was introduced as a cement replacement with the substitution rate at $3 \%$, both the compressive strength and flexural strength of A-3 specimen were almost the same as that of the control specimen (A-0) at all ages. 


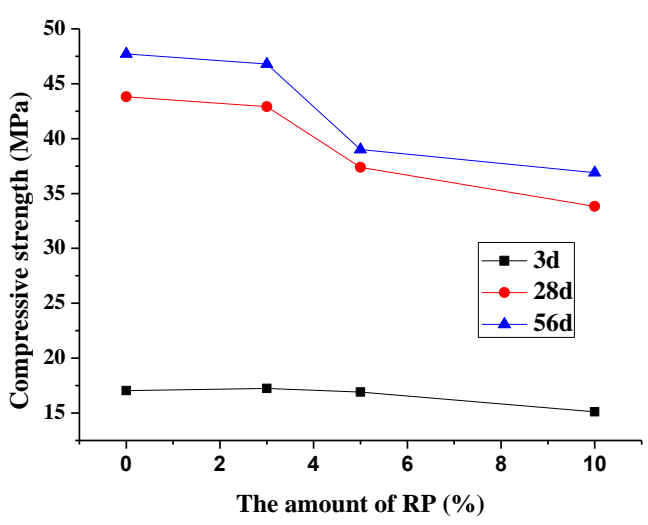

(a) Compressive strength

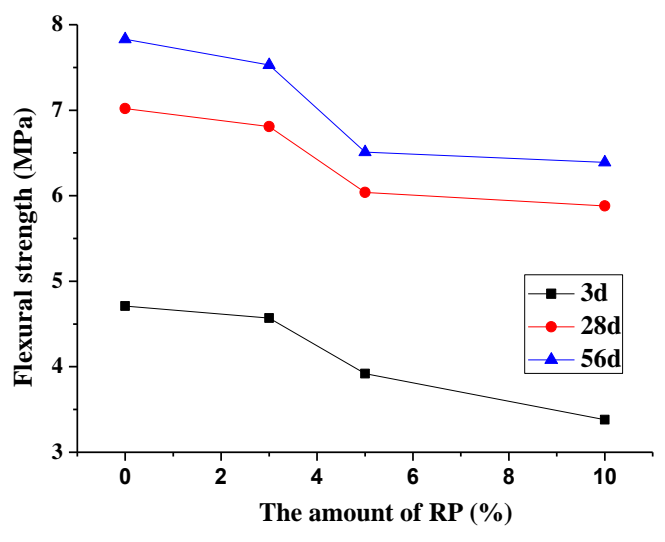

(b) Flexural strength

Fig. 8. Influence of RP on mechanical properties of cement mortar

According to Fig.8, the flexural and compressive properties of A-5 and A-10 specimens showed different trends of changes compared to the control specimen. As curing age increased, the reduction of mechanical strength of A-5 and A-10 samples turned out more significant. The compressive strength on D28 of A-5 and A-10 samples were $14.7 \%$ and $22.8 \%$ lower than that of the control specimen respectively, and the flexural strength of A-5 and A-10 samples were $14.0 \%$ and $16.2 \%$ lower respectively. It could be suggested that to maintain the mechanical properties of mortar products, the replacement rate of RP to cement should not be high than $3 \%$.

\subsection{The influence of RFA on properties of cementitious materials}

In order to determine the effect of RFA-T content on mechanical properties of photocatalytic cement mortar, five mortar specimens were prepared and cured conforming to Chinese Standard Method of testing cements-Determination of strength GB/T 17671 [41]. The NFA was partially replaced with RFA-T at four different substitution rates of 30\%, 50\%, 70\% and $100 \%$. The cementitious material contained $3 \%$ of RP was according to test results obtained in Section 3.1. Detailed mix proportions of mortar specimens containing RFA-T are shown in Table 6. 
Table 6. Mix proportion of photocatalytic cement mortar samples containing recycled fine aggregate $(\mathrm{g})$

\begin{tabular}{|c|c|c|c|c|c|c|}
\hline Code & Cement & RP & NFA & RFA-T & Water & Superplasticizer \\
\hline B-0 & 436.5 & 13.5 & 1350 & 0 & 225 & 4.5 \\
\hline B-30 & 436.5 & 13.5 & 945 & 405 & 225 & 4.5 \\
\hline B-50 & 436.5 & 13.5 & 675 & 675 & 225 & 4.5 \\
\hline B-70 & 436.5 & 13.5 & 405 & 945 & 225 & 4.5 \\
\hline B-100 & 436.5 & 13.5 & 0 & 1350 & 225 & 4.5 \\
\hline
\end{tabular}

The compressive strength and flexural strength were tested at curing ages of D3, D28, and D56 and demonstrated in Fig. 9.

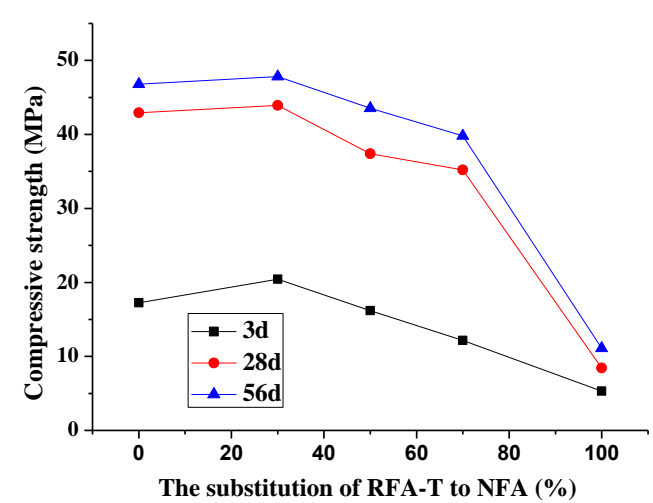

(a) Compressive strength

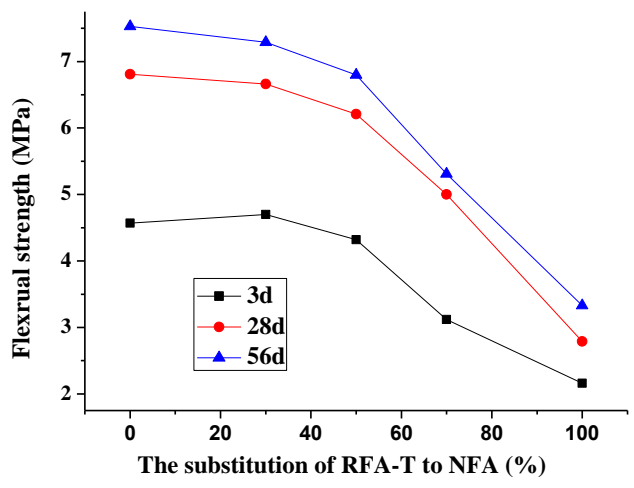

(b) Flexural strength

Fig.9. Influence of RFA-T on mechanical properties of photocatalytic cement mortar

According to Fig.9., the compressive strength of B-30 specimen with 30\% RFA-T content was $18.4 \%$ higher than that of the control specimen (i.e., B-0). This finding was consistent to previous investigation [42] on RAC strength at early ages. The increase in compressive strength of cementitious materials containing lower percentage of RFA could be due to the shape of the RFA which is more angular and rough in surface texture compared to that of NFA [43]. As the content of RFA increased, the compressive strength of mortar decreased significantly, which could be attributed to the high porosity and low mechanical properties of RFA. The flexural strength of mortar specimens showed similar trends. When the substitution rate of RFA-T was lower than $30 \%$, the flexural strength of B-30 specimen was slightly higher than that of the control specimen. 
On D28, the mechanical properties of B-30 specimen were close to that of the control specimen (only $2.4 \%$ higher for compressive strength and $2.2 \%$ lower for flexural strength). Besides D3 and D28, the mechanical properties of specimens on D56 are also plotted in Fig.9. It can be seen in Fig.9 that compared to D28, specimens' mechanical properties on D56 showed similar changes as the substitution rate of RFA increased.

\subsection{The influence of RCA on the properties of cementitious materials}

Further tests on the effects of RCA-T on concrete mechanical properties were performed. The $150 \mathrm{~mm}$ concrete cubes were cast following the mixture proportion listed in Table 7 . The RP accounted for $3 \%$ of cementititous materials by weight. The RFA-T was used to replace $30 \%$ of NFA by weight. Three different substitution rates of RCA-T (i.e., 0, 30\%, and 50\%) were designed to replace NCA. All concrete cubes were cured at the room temperature of $20^{\circ} \mathrm{C} \pm$ $2{ }^{\circ} \mathrm{C}$, with relative humidity around $95 \%$.

Table 7. Mix proportion of photocatalytic concrete based on ECWRM model $\left(\mathrm{kg} / \mathrm{m}^{3}\right)$

\begin{tabular}{|l|c|c|c|c|c|c|c|c|c|}
\hline Code & Cement & Fly ash & RP & NFA & RFA-T & NCA & RCA-T & Water & Superplasticizer \\
\hline C-0 & 358.8 & 93.2 & 14 & 399.7 & 171.3 & 1158 & 0 & 205 & 2.8 \\
\hline C-30 & 358.8 & 93.2 & 14 & 399.7 & 171.3 & 810.6 & 347.4 & 205 & 2.8 \\
\hline C-50 & 358.8 & 93.2 & 14 & 399.7 & 171.3 & 579 & 579 & 205 & 2.8 \\
\hline
\end{tabular}

In Table 7, C-0, C-30, and C-50 denote the three types of concrete specimens with different substitution rates of RCA-T to NCA (i.e., 0, 30\%, and 50\%) in the mix design. Compressive strength of cubes was tested at pre-defined curing ages. Fig.10 illustrates the compressive strength at three different curing ages under various designed substitution rates of RCA-T. 


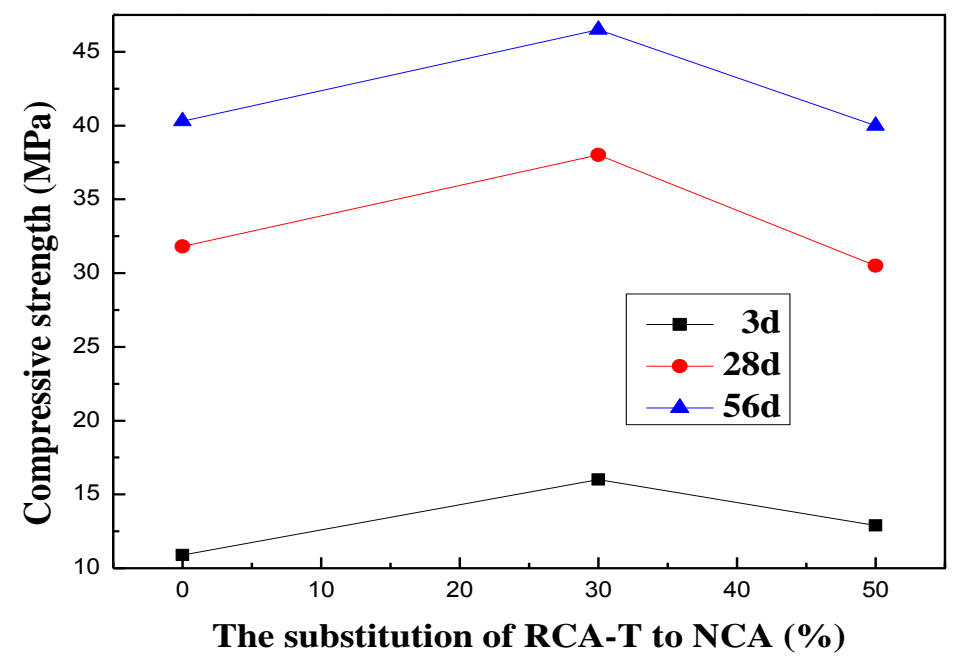

Fig.10. Influence of RCA-T on compressive strength of photocatalytic concrete adopting

\section{ECWRM model}

It was generally perceived that recycled aggregates (RAs) are materials with inferior quality, and concrete strength would be decreased with the increased amount of RAs. However, this study did not show completely consistent observations. As can be seen in Fig.10, the substitution rate of RCA-T lower than 50\% would not decrease the compressive strength of concrete, and the compressive strength could be even higher compared to that of the control group when the substitution rate was 30\%. The earlier study of Xu and Sun [42] showed that RA alone without being soaked in $\mathrm{TiO}_{2}$ also led to similar enhancement of concrete strength. Therefore, RA has certain positive effects on RAC strength either with or without $\mathrm{TiO}_{2}$.

The positive effect of RAs on RAC strength could be explained by the features of RAs such as "internal curing". Similar to lightweight aggregate, the waste cementitious mortar attached to RAs in the concrete mixture could absorb and release moisture using its internal micropores and microtubules. Moisture absorbed by waste mortar would cause partly lower water-to-cement ratio around RAs, therefore reducing the "water pockets" caused by internal 
stratification within bottom layers of aggregates. Further, the concentration and directional arrangement of $\mathrm{Ca}(\mathrm{OH})_{2}$ could be avoided in the interfaces. As a result, the coherent strength of interface between cementitious materials and aggregates could be improved. The "internal curing" feature of RAs described by Jin et al. [44] could be achieved by releasing absorbed moisture, which enhances the further hydration of cementitious materials around the aggregates. Besides, the "internal curing" enables fly ash to hydrate completely with Portland cement and to generate $\mathrm{C}-\mathrm{S}-\mathrm{H}$ gel with low $\mathrm{Ca} / \mathrm{Si}$ ratio. The gels encapsulating aggregates fill the voids between aggregates and cementitous materials and improve the compactness of interface between aggregates and cementitious materials. These features of RAs are perceived with positive effects in mechanical strength of RAC.

However, the lower hardness and stiffness of RAs would negatively affect RAC strength. The dust contained in RAs decreases the bond strength between aggregates and cement paste and creates weak connections within concrete materials, and hence reducing RAC strength. Li et al.[45] and Li et al.[46] further identified the weak interfacial transtion zones (ITZs) between new cementitious materials and old mortars attached in RCA. ITZ is a weak part in RAC [47]. Micro-cracks usually start from ITZs [45, 46]. Therefore, compared to natural aggregates, RAs have both positive and negative features for concrete strength development.

These aforementioned features of RAs could explain the strength change of RAC containing fly ash. When the substitution rate of RCA-T to NCA is $30 \%$, the combined effect of positive and negative features of RAs is optimized and the strength of photocatalytic RAC is higher than that of the control group (i.e., C-0). When the substitution rate is increased from $30 \%$ to $50 \%$, the positive effects of RAs would be gradually counteracted by their negative 
effects. The positive effects of RAs counteract their negative effects at the substitution rate of $50 \%$ based on the fact that the strength of RAC group C-50 was about the same as that of the control group (i.e., C-0). Therefore, it is suggested that the RCA-T proportion in coarse aggregate range from $30 \%$ to $50 \%$ to maintain the RAC mechanical properties.

\section{The experimental test of photocatalytic concrete in degrading $\mathrm{NO}_{2}$}

\subsection{Tests of photocatalytic performance}

The photocatalytic RAC specimens sized at $300 \mathrm{~mm} \times 300 \mathrm{~mm} \times 20 \mathrm{~mm}$ were cast following the mixture design shown in Table $\underline{7}$. The three different types of mixture design (i.e., C-0, C30, and C-50) were applied in the RAC specimens. Following the test program described in Section 2.2, the three correspondingly different types of concrete specimens were tested of their performance in degrading $\mathrm{NO}_{2}$. The comparison of these three different specimens' photocatalytic activities is illustrated in Fig.11, which indicates the capacity of photocatalytic concrete using ECWRM in degrading $\mathrm{NO}_{2}$.

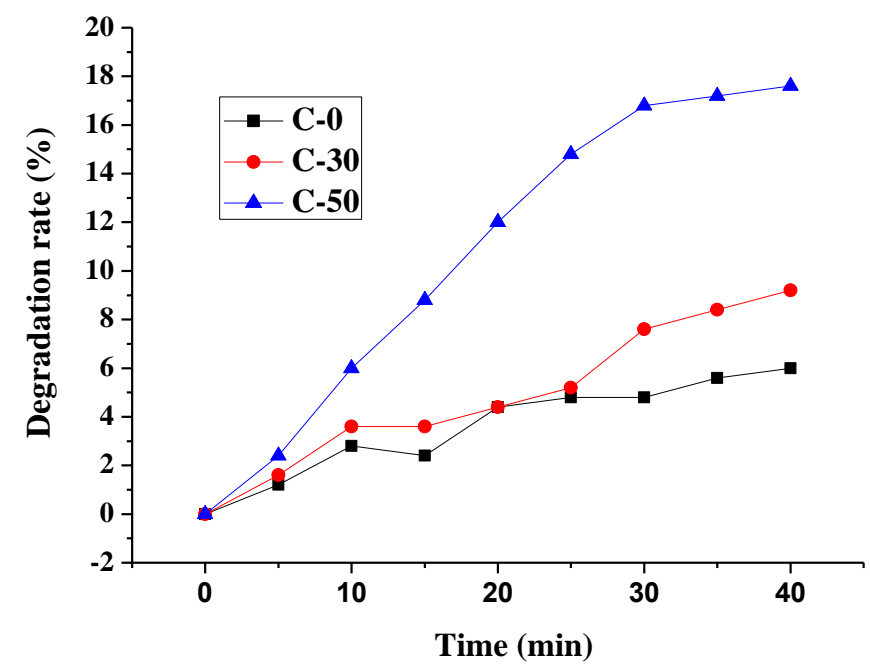

Fig.11. Comparison of degradation rates of $\mathrm{NO}_{2}$ among three different types of concrete 
specimens

The degradation rate of $\mathrm{NO}_{2}$ would increase with the lighting duration for all the three types of specimens. However, the C-0 type specimen showed limited capacity in degrading $\mathrm{NO}_{2}$. The degradation rate of $\mathrm{NO}_{2}$ after 40 min lighting exposure was only $6.0 \%$, due to the fact that merely RFA was coated with $\mathrm{TiO}_{2}$ in $\mathrm{C}-0$ type specimen, and the proportion of RFA was limited to $30 \%$ in fine aggregates. The photocatalytic performance of concrete would be enhanced when RCA-T was added into the concrete mixture by replacing $30 \%$ of natural coarse aggregates. The degradation rate of $\mathrm{NO}_{2}$ in $\mathrm{C}-30$ type of specimen was increased to $9.2 \%$ after 40 min lighting exposure. Further increasing the substitution rate of RCA-T to $50 \%$ of all coarse aggregates would significantly improve the photocatalytic performance of concrete specimen. The degradation rate of $\mathrm{NO}_{2}$ in C-50 concrete specimen was measured at $17.6 \%$.

\subsection{Observation and Discussion}

The micro-structure of recycled aggregates (RAs) within RAC is further observed, accompanied by the X-ray diffractometer analysis for different types of concrete specimens. The growth of $\mathrm{TiO}_{2}$ in RAC is further observed in scanning electron microscope (SEM). Finally, the chemical reactions within $\mathrm{TiO}_{2}$ as the photocatalysts are described to explain how $\mathrm{TiO}_{2}$ degrades hazardous substances in the air.

\subsubsection{Micro-structure of recycled aggregates}

RAs within RAC were observed using Phenom Pro, the desktop SEM. It can be found from Fig.12 and Fig.13 on the change of the micro-structure of RFA. Numerous voids can be found within RAs before it was coated with $\mathrm{TiO}_{2}$. After RAs were soaked in $\mathrm{TiO}_{2}$ solution, $\mathrm{TiO}_{2}$ were attached to the voids of RAs. It was found that $\mathrm{TiO}_{2}$ can be coated to RAs through soaking 
them in $\mathrm{TiO}_{2}$ solution.

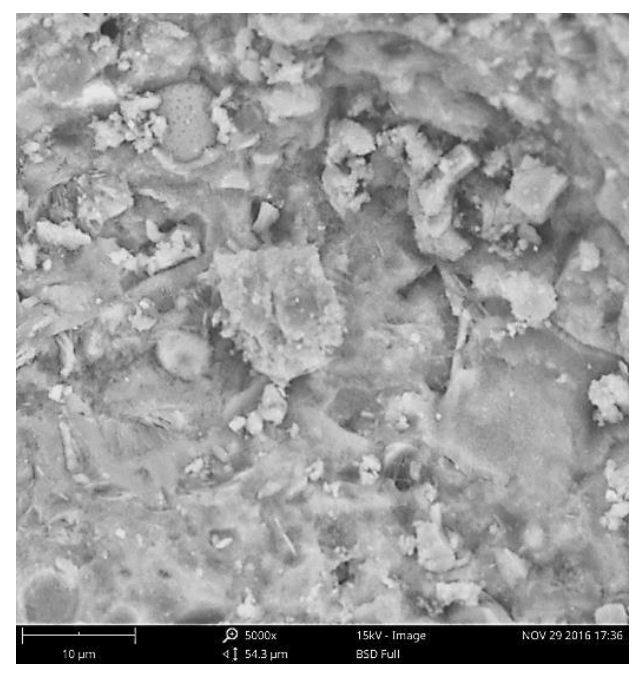

(a) RFA

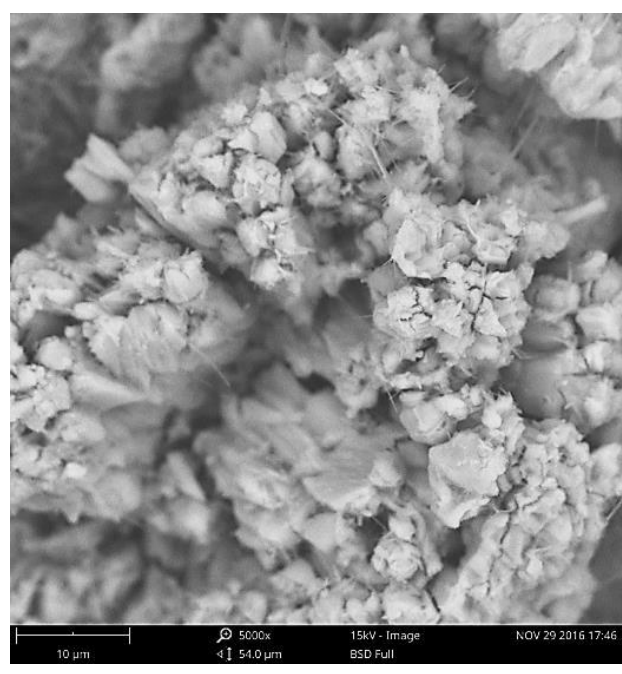

(b) RFA-T

Fig.12. Micro-structure of recycled fine aggregates

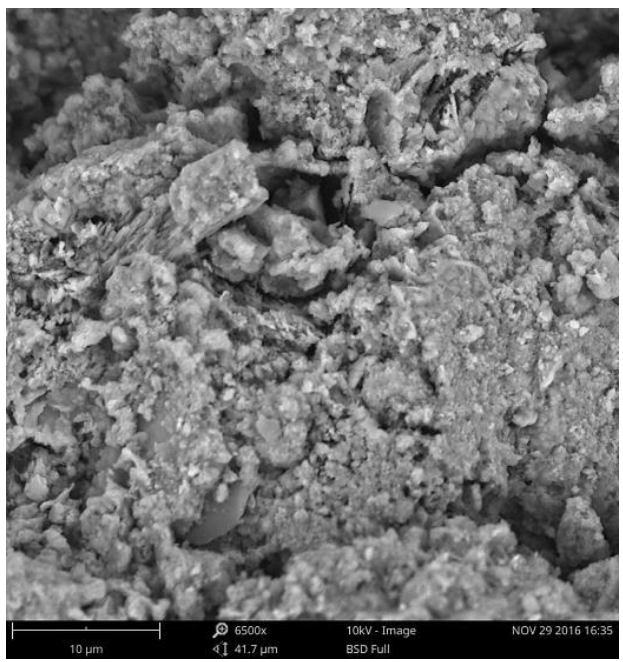

(a) RCA

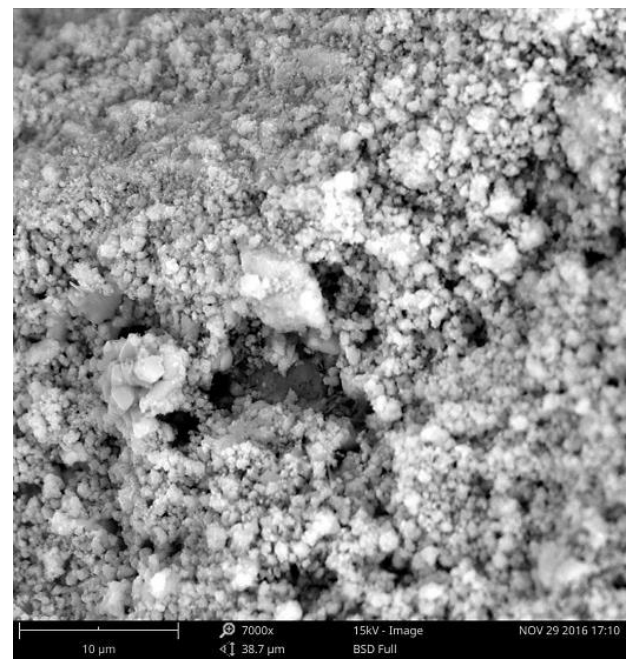

(b) RCA-T

Fig.13. Micro-structure of recycled coarse aggregates

\subsubsection{Phase analysis using $X$-ray diffractometer}

The $\mathrm{TiO}_{2}$ concentration within different types of concrete specimens can be further compared through phase analysis using D8 Advance X-ray diffractometer. The analysis started from crushing the C-0 and C-30 types of concrete specimens on D28. Samples of debris were put into the absolute ethanol to terminate the cement hydration. Then the debris were oven- 
dried until their weight remained constant. Afterwards, the debris were grinded in an agate mortar and sieved at the size of $0.075 \mathrm{~mm}$. After staying in dryer for 24 hours, the phase analysis would be conducted on the sample debris.

It can be found in Fig.14 that the peak intensity of diffraction for C-30 debris was higher than that of $\mathrm{C}-0$ debris, indicating that the $\mathrm{C}-30$ type specimen contained more $\mathrm{TiO}_{2}$. This is consistent with the finding shown in Fig.11, as C-30 specimen had $\mathrm{TiO}_{2}$ in both RFA and RCA, compared to C-0 type specimen with only RFA coated with $\mathrm{TiO}_{2}$.

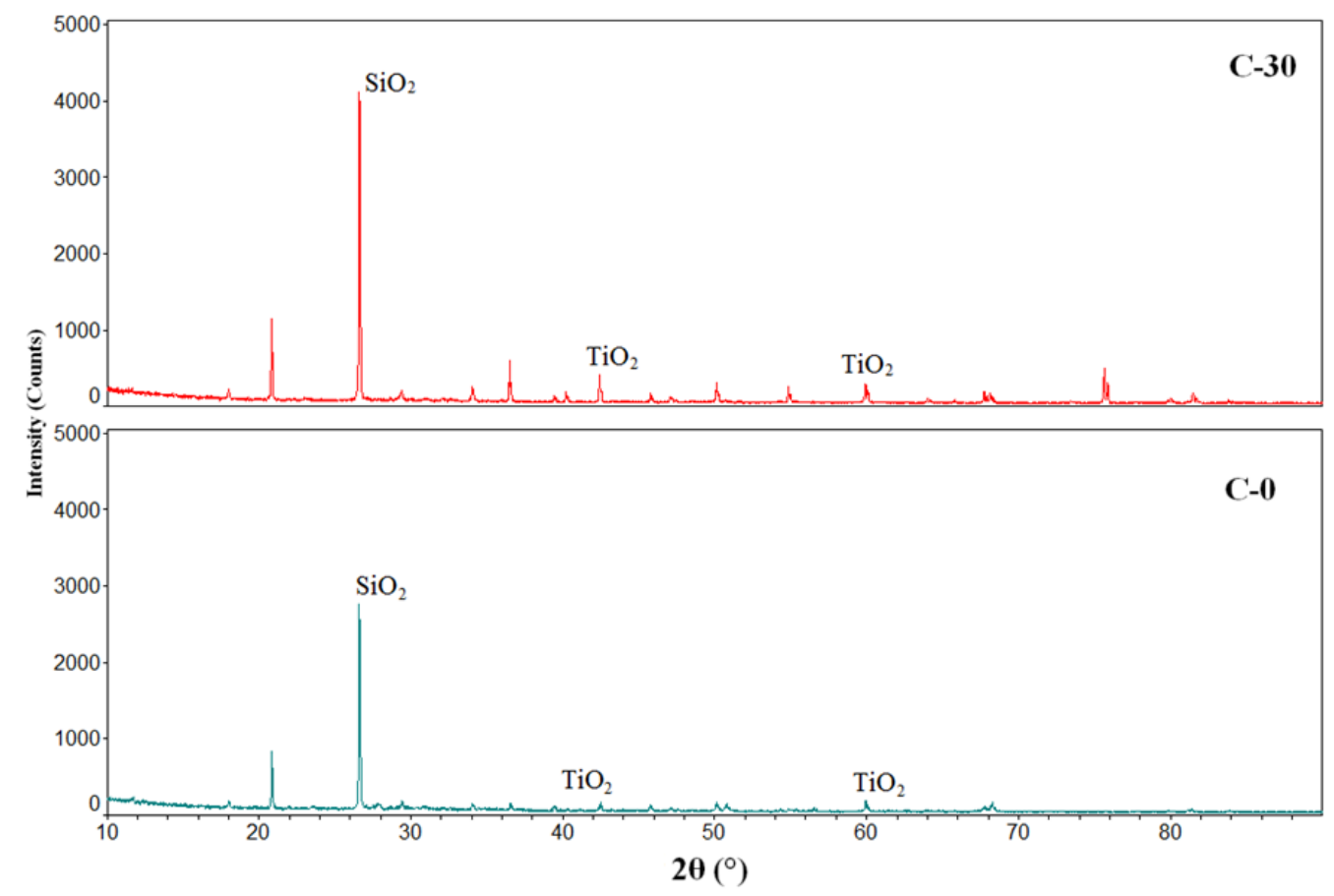

Fig.14. X-ray analysis of concrete specimen debris

\subsubsection{Observations on $\mathrm{TiO}_{2}$-driven whiskers within recycled aggregates}

To further study the growth of $\mathrm{TiO}_{2}$ within $\mathrm{RAC}$, extra samples of debris sized between 10 $\mathrm{mm}$ and $20 \mathrm{~mm}$ containing the interface of RCA and mortar were collected from crushed specimens. The debris were put in anhydrous ethanol to stop the cement hydration, and then 
oven-dried until its weight was unchanged. Fig.15 shows the micro-structure of debris using Phenom Pro SEM.
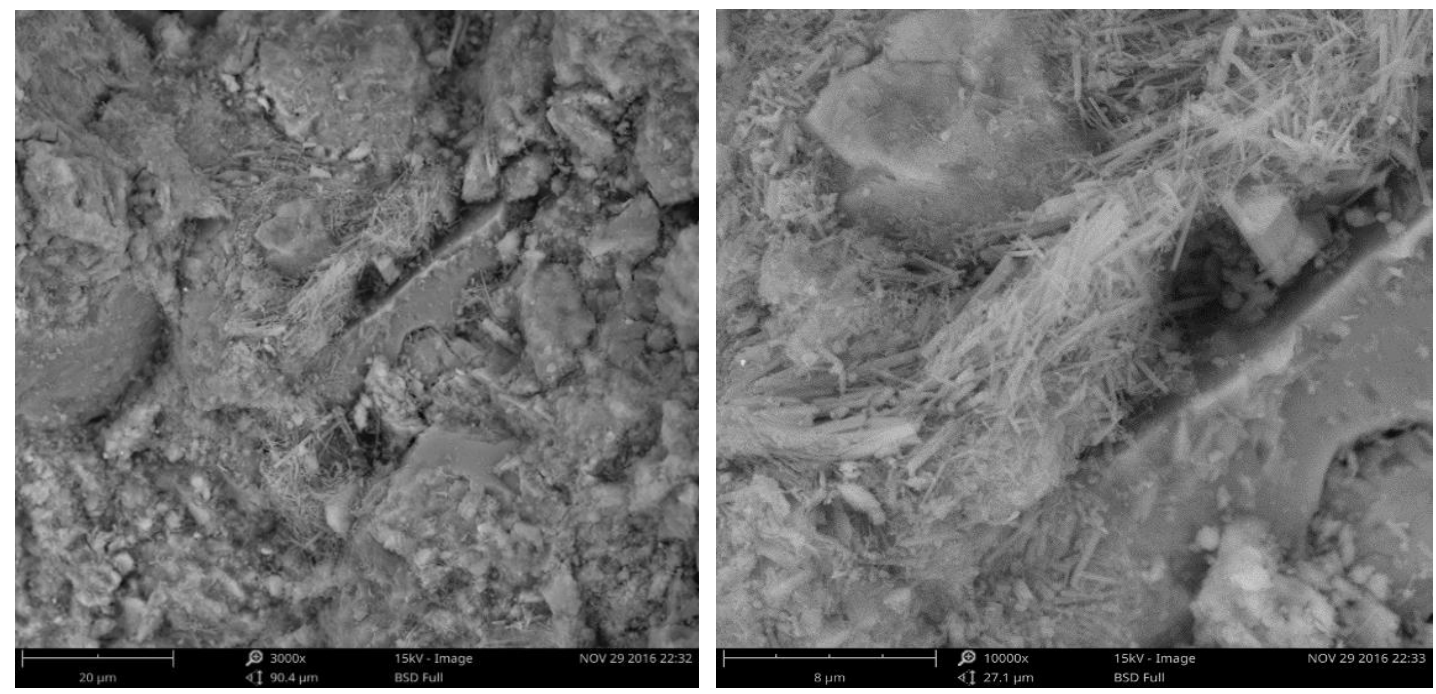

Fig.15. The micro-structure of photocatalytic RAC adopting ECWRM

According to Fig.15, the whiskers resulted from adding $\mathrm{TiO}_{2}$ into RCAs fill the porosity within RAs. Filling RAs' internal voids with $\mathrm{TiO}_{2}$-driven whiskers enhances the concrete strength growth. $\mathrm{TiO}_{2}$-driven whiskers were found in both the surface and and inner of RAs.

\subsubsection{Discussion}

The micro-structure observation and X-ray test indicated consistent results with the photocatalytic performance evaluation that $\mathrm{TiO}_{2}$ particles could be introduced to fill the internal voids of RAs and to further enable RAC to absorb hazardous substances in the air. This photocatalytic activity tests performed in this research bridges RAC and air depollution by introducing the "passive strategy" into RAC. Although coating 30\% of RCA and 30\% of RFA with $\mathrm{TiO}_{2}$ still displays limited capacity in absorbing $\mathrm{NO}_{2}$ with degradation rate at $17.6 \%$, the degradation capacity could be further improved by introducing pervious or porous RAC to increase the contact surface between aggregates and the air. The approach of filling RA porosity 
with $\mathrm{TiO}_{2}$ particles by pre-treating RAs could also be expanded to the study of general lightweight aggregate concrete, where nano-photocatalysts could also fill the internal voids within lightweight aggregates for air depollution purpose. The current research could also motivate further studies of comparing the photocatalytic performance of pervious concrete containing RAs intertwining with nano-photocatalysts to that of the conventional concrete whose surface is coated with the same type of nano-photocatalysts. Based on this study, more state-of-the-art research can be performed by utilizing both $\mathrm{TiO}_{2}$-soaked $\mathrm{RAs}$ and graphene oxide-dispersed cement composites [48] to enhance concrete properties in terms of strength and photocatalytic effects.

\section{Conclusions}

This research targeted the photocatalytic concrete specimens adopting the entire concrete waste reuse model (ECWRM) to degrade $\mathrm{NO}_{2}$. The experimental investigation can be divided into two major stages. In the first stage, cementitious products including mortar and concrete using byproducts of crushed old concrete from local waste streams were tested of their mechanical properties. The first stage aimed to identify proper replacement rates of recycled power (RP), recycled fine aggregate (RFA), and recycled coarse aggregate (RCA) in replacing cementitious materials, natural fine aggregate (NFA), and natural coarse aggregate (NCA) respectively in concrete mixture design without deteriorating concrete mechanical properties. The second stage of the research tested and evaluated the three different types of concrete specimens (i.e., C-0, C-30, and C-50) in their capacities of degrading $\mathrm{NO}_{2}$. The micro-structure of photocatalysts within recycled aggregate concrete (RAC) under SEM was observed. The photocatalytic reactions of $\mathrm{TiO}_{2}$-coated $\mathrm{RAC}$ were described based on the theory of generation of electronhole pair in $\mathrm{TiO}_{2}$. Major findings can be summarized below:

- Up to $3 \%$ replacement rate of RP to cementitious materials, $30 \%$ replacement rate of 
RFA to NFA, and 50\% of RCA to NCA would not reduce the compressive strength of concrete specimens.

- The substitution rate at $30 \%$ of RCA to NCA would improve the mechanical properties of concrete. The rationale could be explained by the balance between positive effects (e.g., "internal curing" similar to that in lightweight aggregate) and negative factors (e.g., lower hardness) within recycled aggregates.

- The substitution rate of RCA to NCA is suggested to be between $30 \%$ and $50 \%$. As the replacement rate of RAC is increased from $30 \%$ to $50 \%$, the positive attributes of recycled aggregates would be gradually counteracted by their inferior qualities.

- For up to 40 min exposure of concrete specimens to UV light, C-0 type specimen, which has only RFA coated with $\mathrm{TiO}_{2}$, showed limited capacity in degrading $\mathrm{NO}_{2}$. However, C-30 and C-50 type specimen, which had both RFA and RCA coated with $\mathrm{TiO}_{2}$, would display significantly improved capacity in degrading $\mathrm{NO}_{2}$. This improvement was especially more significant within C-50 type specimen, when 50\% of NCA was replaced by RCA.

- Observations of micro-structures of recycled aggregates revealed that soaking recycled aggregates in $\mathrm{TiO}_{2}$ solution enabled whiskers of $\mathrm{TiO}_{2}$ to fill the internal voids within recycled aggregates. This was tested through the X-ray analysis in measuring the peak intensity of diffraction in concrete debris. Filling voids within recycled aggregates with $\mathrm{TiO}_{2}$ as the photocatalysts could enhance concrete mechanical properties and also enable the photocatalytic concrete adopting ECWRM to absorb $\mathrm{NO}_{2}$.

- This study provides the initial insights of applying the "passive strategy" (i.e., photocatalytic activities) to RAC through filling internal voids of $\mathrm{RAs}$ with $\mathrm{TiO}_{2}$ particles. Based on the current research findings, further studies could be adopted in porous concrete to increase the contact surface of photocatalysts in recycled aggregates to the air, for the purpose of increasing the degradation of hazardous substances. The photocatalytic performance of $\mathrm{RAC}$ can be compared to that of the traditional approach by coating $\mathrm{TiO}_{2}$ to the conventional concrete surface. 


\section{Acknowledgments}

The authors wish to acknowledge the financial support of National Science and Technology Support Program of China (Grant No. 2015BAL02B03), Natural Science Foundation of Ningbo (Grant No. 2015A610297), Ningbo Social Development Project (Grant No. 2012C50047), National Natural Science Foundation of China (Contract No. 51778577), and Ningbo the Benefit of People Program from the Ningbo Science and Technology Bureau (Contract No. 2015C50049). The authors would also like to acknowledge the Writing Retreat Fund provided by University of Brighton.

\section{Reference}

[1] M.M. Hassan, H. Dylla, L.N.Mohammad, Evaluation of the durability of titanium dioxide photocatalyst coating for concrete pavement, Const. Build. Mater. 24(2010) 1456-1461.

[2] M.M. Ballari, Q.L. Yu, H.J.H. Brouwers, Experimental study of the $\mathrm{NO}$ and $\mathrm{NO}_{2}$ degradation by photocatalytically active concrete. Catal. Today. 161(2011) 175-180.

[3] J. Yang, G. Wang, D. Wang, A self-cleaning coating material of $\mathrm{TiO}_{2}$ porous microspheres/cement composite with high-efficient photocatalytic depollution performance, Mater. Lett. 200 (2017) 1-5.

[4] D.E. Macphee, A. Folli, Photocatalytic concretes - The interface between photocatalysis and cement chemistry, Cement Concrete Res. 85 (2016) 48-54.

[5] M. Faraldos, R. Kropp, M.A. Anderson, Photocatalytic hydrophobic concrete coatings to combat air pollution, Catal. Today. 259 (2016) 228-236.

[6] J. Chen, C. Poon, Photocatalytic activity of titanium dioxide modified concrete materials - Influence of utilizing recycled glass cullets as aggregates, J. Environ. Manage. 90(2009) 3436-3442.

[7] C.S. Poon, E. Cheung, NO removal efficiency of photocatalytic paving blocks prepared with recycled materials, Const. Build. Mater. 21(2007) 1746-1753.

[8] C. Shi, Y. Li , J. Zhang, Performance enhancement of recycled concrete aggregate - A review. J. Clean. Prod. 112(2016) 466-472.

[9] V.W.Y. Tam, X.F., Gao, C.M. Tam, K.M. Ng, Physio-chemical reactions in recycle aggregate concrete, J. Hazard. Mater. 163 (2009) 823-828.

[10] J. Shi, Y. Xu, Estimation and forecasting of concrete debris amount in China, Resour. Conserv. Recy. 49(2006) 147-158.

[11] R. Jin, B. Li, T. Zhou, D. Wanatowski, P. Piroozfar, An empirical study of perceptions towards construction and demolition waste recycling and reuse in China, Resour. Conserv. Recy. 126 (2017) 8698.

[12] Y. Xu, C. Qian, J.Y. Sun, Microstructure of interface transition zone in high performance recycled aggregate concrete, Singapore, 2010, 1221-1225.

[13] P. Zhu, X.Q. Mao, W. Qu, Investigation of using recycled powder from waste of clay bricks and cement solids in reactive powder concrete, Const. Build. Mater. 113(2016) 246-254.

[14] M.C. Limbachiya, T. Leelawat, R.K. Dhir, Use of recycled concrete aggregate in high-strength concrete, Mater. Struc. 33(2000) 574-580.

[15] V.W. Tam, K. Wang, C.M. Tam, Assessing relationships among properties of demolished concrete, recycled aggregate and recycled aggregate concrete using regression analysis, J. Hazard. Mater. 
152(2008) 703-714.

[16] J. Xiao, J. Li, C. Zhang, Mechanical properties of recycled aggregate concrete under uniaxial loading, Cement Concrete Res. 35(2005) 1187-1194.

[17] Y. Zhao, W. Zeng, H. Zhang, Properties of recycled aggregate concrete with different water control methods, Const. Build. Mater. 152 (2017) 539-546.

[18] X.S. Shi, F.G. Collins, X.L. Zhao, Mechanical properties and microstructure analysis of fly ash geopolymeric recycled concrete, J. Hazard. Mater. 237-238(2012), 20-29.

[19] C. Fan, R. Huang, H. Hwang, Properties of concrete incorporating fine recycled aggregates from crushed concrete wastes, Const. Build. Mater. 112(2016) 708-715.

[20] J. Geng, J. Sun, Characteristics of the carbonation resistance of recycled fine aggregate concrete, Const. Build. Mater. 49 (2013) 814-820.

[21] B.M.V. Kumar, H. Ananthan, K.V.A. Balaji, Experimental studies on cement stabilized masonry blocks prepared from brick powder, fine recycled concrete aggregate and pozzolanic materials, J. Build. Eng. 10(2017) 80-88.

[22] P. Zhu, X. Mao, W. Qu, Investigation of using recycled powder from waste of clay bricks and cement solids in reactive powder concrete, Const. Build. Mater. 113(2016) 246-254.

[23] V. Letelier, E. Tarela, G. Moriconi, Mechanical Properties of Concretes with Recycled Aggregates and Waste Brick Powder as Cement Replacement, Procedia Eng. 171(2017) 627-632.

[24] Y. Koshiro, K. Ichise, Application of entire concrete waste reuse model to produce recycled aggregate class H, Const. Build. Mater. 67(2014) 308-314.

[25] O. Ginés, J.M. Chimenos, A. Vizcarro, J. Formosa, J.R. Rosell, Combined use of MSWI bottom ash and fly ash as aggregate in concrete formulation: Environmental and mechanical considerations, J. Hazard. Mater. 169 (2009), 643-650.

[26] N.U., Kockal, T. Ozturan, Effects of lightweight fly ash aggregate properties on the behavior of lightweight concretes, J. Hazard. Mater. 179(2010) 954-965.

[27] M. Gesoglu, E. Güneyisi, S.F. Mahmood, H. Ö. Öz, K. Mermerdas, Recycling ground granulated blast furnace slag as cold bonded artificial aggregate partially used in self-compacting concrete, J. Hazard. Mater. 235-236 (2012) 352-358.

[28] S. Erdem, M.A. Blankson, Environmental performance and mechanical analysis of concretecontaining recycled asphalt pavement (RAP) and waste precastconcrete as aggregate, J. Hazard. Mater. 264 (2014), 403-410.

[29] D. Xuan, B. Zhan, C.S., Poon, W. Zheng, Innovative reuse of concrete slurry waste from readymixed concreteplants in construction products, J. Hazard. Mater. 312 (2016) 65-72.

[30] C. Wang, X, Lin, M. He, D. Wang, S, Zhang, Environmental performance, mechanical and microstructure analysis of concrete containing oil-based drilling cuttings pyrolysis residues of shale gas, J. Hazard. Mater. 338 (2017) 410-427.

[31] China Standards Publication, Common Portland Cement; GB 175-2007, China Standards Press: Beijing, China, 2007 (in Chinese).

[32] China Standards Publication, Fly Ash Used for Cement and Concrete; GB/T1596-2005, China Standards Press: Beijing, China, 2005(in Chinese).

[33] China ISO Standard Sand, GSB 08-1337-2014, Standardization Administratin of the P.R.C, Beijing, China, 2014(in Chinese).

[34] China Standards Publication. Pebble and crushed stone for construction; GB/T 14685-2011; China 
Standards Press: Beijing, China, 2011(in Chinese).

[35] China Standards Publication, Sand for construction; GB/T 14684-2011, China Standards Press: Beijing, China, 2011 (in Chinese).

[36] China Standards Publication, Test method of photocatalytic materials for air purification, GB/T 23761-2009, China Standards Press: Beijing, China, 2009 (in Chinese).

[37] China Standards Publication, UV light sources for testing properties of photocatalytic materials, GB/T 30809-2014, China Standards Press: Beijing, China, 2014(in Chinese).

[38] Q. Zeng, K. Li, F.T. Chong, Determination of cement hydration and pozzolanic reaction extents for fly-ash cement pastes, Const. Build. Mater. 27(2012) 560-569.

[39] N. Schwarz, N. Neithalath N, Influence of a fine glass powder on cement hydration: Comparison to fly ash and modeling the degree of hydration, Cement Concrete Res. 38(2008) 429-436.

[40] Y.M. Zhang, W. Sun, H.D. Yan, Hydration of high-volume fly ash cement pastes, Cement Concrete Comp. 22(2000) 445-452.

[41] China Standards Publication, Method of testing cements-Determination of strength GB/T 17671, China Standards Press: Beijing, China, 1999 (in Chinese).

[42] Y. Xu, J. Sun, Influence of recycled aggregate on physical and mechanical properties of high performance recycled aggregate concrete, Key Eng. Mater. 460-461(2011) 764-767.

[43] N.K. Bui, T. Satomi, H. Takahashi, Improvement of mechanical properties of recycled aggregate concrete basing on a new combination method between recycled aggregate and natural aggregate, Const. Build. Mater. 148(2017) 376-385. 